\title{
iCap: Intralingual Captioning for Writing and Vocabulary Enhancement
}

\author{
Noa Talaván \\ Jennifer Lertola \\ Tomás Costal \\ Universidad Nacional de Educación a Distancia (UNED) \\ University of Bologna, Italy \\ ntalavan@flog.uned.es, jennifer.lertola@gmail.com, xuncoenglish@gmail.com
}

\begin{abstract}
The research on the use of active captioning or subtitling in foreign language learning has considerably increased in the course of the last decade, although there is still lack of evidence as regards the potential advantages of intralingual captioning in this context. The present project attempts to fill this void by analysing the didactic use of intralingual subtitling in a distance learning environment both in terms of written production and vocabulary acquisition. To this end, a total number of 41 undergraduate English B1 students have been working on 10 sequenced subtitling activities using short pre-selected videos taken from an American sitcom in the course of a month and a half. Peer-to-peer assessment has also been fostered during the project through active use of online forums. The conclusions confirm the expected benefits as far as writing and vocabulary skills enhancement is concerned and provide further insights into how to best implement this practice.
\end{abstract}

Keywords: audiovisual translation, intralingual subtitling, distance language learning, written production, vocabulary acquisition 


\section{Introduction}

iCap, Intralingual Captioning in Foreign Language Education, was a project undertaken during the course 2013-14 at the UNED, Universidad Nacional de Educación a Distancia, in Spain. Within an online collaborative context, students were asked to provide intralingual subtitles (English-English) for ten videos extracted from an American TV series. This task-based oriented didactic approach was directed to assess the potential effects of this type of same-language subtitling to improve writing skills and vocabulary acquisition.

Although the research field that studies the pedagogical benefits of subtitling in foreign language (henceforth, L2) education has been gaining increasing attention in recent years, the study of the effects of intralingual captioning to improve written production and vocabulary learning has not been among the main foci of interest yet.

From a pedagogical point of view, when students have to produce same-language subtitles in the L2, there are a series of key elements they can profit from. When creating subtitles, they can enhance their writing-related skills, given that they will have to work on register and style selection, sequencing of ideas, correct use of cohesion and coherence (learning to guide the reader through the message) and spelling, among others. Students were asked to create intralingual subtitles (condensing and segmenting the information as appropriate) and not a mere transcription of the dialogues.

In terms of lexical acquisition, the active production of intralingual subtitles makes L2 students intensively listen ${ }^{1}$ and so encounter new vocabulary, forces them to repeat some words and phrases just as they appear in the original, and gives them the opportunity to work on rephrasing, since they need to condense the message and they have to look for synonyms or alternative ways of reproducing the same semantic concept; finally, learners also need to react to the original when they look for new vocabulary, previously unknown to them. Hence, listen and repeat, typical strategies of vocabulary learning, have a key role that is complemented by more active task-based actions, such as rephrasing and reacting, that can provide learners with multiple channels of real lexical retention.

A final total number of 41 undergraduate English B1 students participated in the iCap project from beginning to end, subtitling the corresponding 10 videos using the platform ClipFlair and providing peer-to-peer feedback through the online forums. ClipFlair (www.clipflair.net) is an online platform designed to use AVT in L2 education (Sokoli, 2015) and it contains a subtitle editor that allows teachers and students to profit from complete ready-to-use activities (including the video, the instructions, and an adaptable subtitling component to help learners with spotting whenever necessary, among other possibilities).

Through a triangulation of quantitative and qualitative methods, making use of diverse data gathering tools (writing and vocabulary pre-tests and post-tests, initial and final questionnaires, and observation), a series of relevant conclusions as far as the possible benefits of intralingual captioning as a didactic tool to improve L2 writing and vocabulary skills have been derived, as will be described in the following sections. 


\section{Theoretical framework}

The use of subtitles for didactic purposes and, more specifically, their use in the field of L2 learning has been an increasingly productive subject of discussion in the academic field over the last two decades. Given its specialised scope, the present study will only mention in passing a few of the greatly abundant applications of audiovisual translation modalities to the enhancement of language learning environments and processes. Hence, reference will be made to a number of publications in which the use of subtitles has been researched in conjunction with techniques such as dubbing, voice-over, narration, audiodescription, and other types of revoicing or combinations thereof, with very promising results derived from the careful analysis of both qualitative and quantitative data. Therein, the inclusion of ample accompanying evidence points to the convenience, appropriacy and even the urgent necessity to further exploit these valuable resources on the basis of their proven efficiency and effectiveness.

Before doing so, it must be noted that in a somewhat contradictory research study on the use of subtitling (European Commission, 2009), European institutions missed the opportunity to present subtitles as an educational and awareness-raising tool. Where it could have been stated that subtitles contribute to linguistic accessibility for all citizens and ameliorate students' competences of oral reception and production, written reception and production, translation, and mediation, the report focused to such a degree on the provisos that the overall impression was that of an encumbrance rather than an encouragement to modify traditional everyday practices. One section of the report (European Commission, 2009: 16) reads as follows:

The literature in this area states that subtitling can contribute to language learning, to a greater or lesser degree of effectiveness, depending on different variables: (a) being accustomed to subtitling [...]; (b) the learner's level [...]; (c) the objectives of the teaching $[\ldots]$; (d) proximity between languages $[\ldots]$

These observations, which could be applied to subtitling in the same way that they could be applied to any other language learning technique past or present, make an unjustified generalisation which imposes a series of prerequisites on the basis of few non-longitudinal, non-experimental studies. Later in the same document (European Commission, 2009: 16-17), observations are made on the alleged problems subtitles may cause learners:

For the role of subtitling to be effective, there must be a semantic correspondence between the pictures and the verbal message, even if this can give rise to comprehension problems, particularly among learners not accustomed to the techniques of subtitling. When the picture serves as the vehicle for part of the information that contributes to getting the message across (figures, names of places or persons written in the picture, etc.), comprehension problems can emerge. 
Again, the presumed obstacles of subtitling, unsupported by comparative long-term analyses, are given more prominence than its advantages in a publication that was commissioned by the executive branch of a supranational organisation with the sole aim of producing a common framework to support citizenship, language policy and innovative practices in multilingual education. Notwithstanding, the most relevant contradiction comes into play when the statistical results of the intra-European battery of questionnaires are discussed at the end (European Commission, 2009: 26):

Three main conclusions may be drawn from these results (to be taken with the precautions mentioned throughout the analysis): subtitling helps to improve the mastery of foreign languages; subtitling can raise awareness and provide motivation for language learning, in both formal and informal contexts, and consequently contributes to creating an environment that encourages multilingualism; knowledge of foreign languages and university studies encourage citizens to choose subtitling rather than dubbing.

Since the extent of the aforementioned 'precautions' is never determined, the impact of this report is clearly detrimental to the advancement of subtitling as a technique to be used in European classrooms for several reasons: (a) the document supports its preliminary conclusions and recommendations solely on questionnaires, which provide qualitative information -thus the 'precautions'; (b) the document is selective in its interpretation of the conclusions made public through academic papers; and (c) preferences and personal appreciations are weighted against linguistic theory, even though there was sufficient evidence at the time to advocate subtitling as a beneficial and versatile technique which could easily be implemented in the language classroom curricula providing that an adequate methodology were to be followed. In brief, one of the foundational studies at the European level, which is still being quoted, discussed and debated almost a decade over, could not manage to provide a solid groundwork from which to build up new knowledge to do with didactic applications of subtitles and subtitling.

The present study will contribute to the refutation of this unsuccessful attempt and, in light of more recent publications by the same institution, it will also bring to the fore all of those points which were neglected, omitted or forgotten in the past. It should remain clear that the prime objective of the iCap project, which ensures consistency with the references detailed below, is to advance empirical data to support the claim that the use of subtitles as a tool for language learning is beneficial. It is also important to remark that using subtitles as a tool could be considered akin to learning via subtitling active subtitling, that is, producing subtitles for a particular purpose and to respond to a particular need. Hence, a distinction should be drawn between this study and others in which subtitles are used only as a support for language learning (cf. Danan, 2015; Vanderplank, 2015).

As specified in a report (European Commission, 2012) on crowdsourcing and translation, far from being on a pilot stage, subtitling has already become a multifaceted linguistic phenomenon. Individuals, groups of individuals and not-for-profit organisations, with or without members who are conversant in formal translation 
studies, access audiovisual content in a foreign language via disinterested contributions to a common online resource pool. If audiovisual products are officially acknowledged as an ideal means for the transmission and promotion of culture, then it would immediately follow that subtitle production and dissemination, as long as it abides by the copyright legislation in force at the time, is indeed a creative linguistic activity whose impact is anything but negligible. Such exponents of communicative translation or mediation (cf. Council of Europe, 2001: 14-15), which have been able to acquire the most complex forms on its own self-regulated way through the channels of informal learning, should be taken advantage of in formal learning environments as well.

The institutional shift in discourse in later pronouncements is quite remarkable: in the 2009 study, didactic uses of subtitling came hand in hand with warnings and limitations; a few years later, popular culture phenomena were taken as a model to be looked up to, even from a theoretical standpoint. What follows is a succinct overview of the level of attention to detail that is paid to fansubbers in their collaborative crowdsourced translations (European Commission, 2012: 35-36):

Offering versions which are very faithful to the original, both from a linguistic and a cultural point of view, and subtitles on markets where dubbing is the rule, fansubbers translate into practice, at least to a certain extent, Venuti's foreignising approach and reject domestication as an impoverishment which does not allow appreciating the original to the full.

The extent to which agreed upon quality standards and particular translation theories are employed is in direct correlation to the expertise of a given fansubbing community and the goals they have set themselves. Therefore, it should be added that, if accessibility services such as subtitling or dubbing can respond to the demands of a given community, meet their expectations, and bridge the gap between two or more cultures, the question remains: why should these tools be avoided in formal educational environments and sequenced learning? This Copernican turn will eventually lead to a complete redefinition of what the institutions understand 'translation' to be, and a much needed reconsideration of what can feasibly be achieved with the help of subtitling. Let us compare the comments which opened this section with the following excerpt (European Commission, 2013: 21): "The production of subtitles can also be a mode of independent language learning, increasingly within online groups of volunteer subtitlers. There are indications that non-professional subtitlers join these groups in order to improve their language skills (Bogucki, 2009; Orrego-Carmona, 2011)."

Fansubbing and language skills improvement had already been covered in an interview with Jorge Díaz-Cintas (cf. European Commission, 2012: 65-72), where the author expressed his views on the multiple didactic uses of subtitling, which would lead us to think that the mere existence of 'indications' would be a considerable understatement. In fact, there is a growing body of specialised literature on the subject of audiovisual translation which backs the idea of fansubbing communities as blossoming spaces of cultural exchange and reflection, albeit the absence of European 
norms and standards has led to the emergence of a plethora of divergent style guidelines (cf. Massidda, 2015).

Back in 2006, Talaván started to analyse the diverse applications of subtitling in second and foreign language learning, paying heed to the potential impact of this tool on the students' competences. The author, however, was very much aware of the main impediments and inexplicable prejudices which were wielded against the use of subtitles in formal learning environments: from the promotion of 'passive' learning to the presumably insignificant repercussions the technique might have on beginners and lower-intermediate students. The use of authentic materials rather than adaptations, the development of higher level audiovisual competences which bring together several of the traditional linguistic skills, the increased levels of motivation and student engagement with the task at hand, and a more in-depth understanding of cultural difference are only a few of the benefits subtitles have to offer in well-planned projectbased teaching methodologies.

The effects of subtitling as an active task on language learners have been approached from different experimental perspectives: both intra- and interlingually with advanced undergraduate students of translation (Incalcaterra McLoughlin, 2009); interlingually concentrating on listening comprehension enhancement (Talaván, 2011 and Talaván \& Rodríguez-Arancón, 2015); interlingually with beginner undergraduate students of a second language, paying special attention to vocabulary acquisition and recall (Lertola, 2012); intralingually with primary foreign language teachers-to-be, measuring the impact on their future eight-year-old students as well as the workflows of the undergraduates themselves (López Cirugeda \& Sánchez Ruiz, 2013); intralingually with a focus on cultural and intercultural awareness (Borghetti \& Lertola, 2014); statistically over a period of four years highlighting the long-term impact and degree of recall of certain vocabulary items (Incalcaterra McLoughlin \& Lertola, 2014); interlingually (in its reverse form), specifically addressing written production (Talaván \& Rodríguez-Arancón, 2014 and Talaván et al. 2016); and interlingually (in its reverse form) in tandem with reverse dubbing with undergraduate students of a distance university (Talaván \& Ávila Cabrera, 2015).

\section{The study}

The iCap project was developed at the UNED within a Teaching Innovation Research Network together with the Universidad de Zaragoza and the National University of Ireland, Galway (NUIG). The project analyses the use of intralingual subtitling as a didactic resource in a distance learning context and its benefits both in terms of written production and vocabulary acquisition. A total number of 41 participants worked on 10 sequenced ClipFlair activities using short (2 minutes approx.) pre-selected videos taken from the American sitcom How I Met Your Mother (Carter Bays and Craig Thomas, 2005-2014) over a period of a month and a half. Participants were required to provide intralingual English subtitles -as condensed as possible without losing semantic 
content- for each of the videos following the instructions contained in the ClipFlair activities. The study applied a mixed method design as it employed quantitative as well as qualitative data collection tools in the form of language assessment tests (writing and vocabulary pre- and post-tests), initial and final questionnaires and observation carried out by four teachers and one tutor who were monitoring the whole project (through forums, assessment and a final video conference).

\subsection{Participants}

A total of 70 first-year undergraduate B1 English students within the English Degree at UNED requested enrolment in the iCap project. The project was presented as a complementary activity and participants could obtain one additional point to their final mark if they finished all the activities. The dropout rate was relatively high, with only 41 students completing the activities; this tendency is typically attributed to the particular characteristics of distance learning methodology (e.g., the great majority of interactions occur asynchronously, and participants may organise their work schedule as they see fit, since they normally work and study and even live in different time zones).

In order to gather background information about the participants, subjects were asked to fill in an initial questionnaire at the beginning of the project. This questionnaire revealed that the mean age was 33 years old and that the great majority of participants were female (73\%) Spanish native speakers (87\%). Besides, most of the students $(81 \%)$ had previously used audiovisual products in the language classroom and they had also made use of interlingual (71\%) and intralingual (47\%) subtitles as a support. However, the majority (94\%) had never experienced active subtitling before; among those who had already tried subtitling, one did it within a previous research network at UNED while the rest claimed to be fansubbers. Finally, participants' expectations about the project were to improve the following skills in this order: written production, listening comprehension, vocabulary acquisition, oral production, reading comprehension and ICT skills.

In fact, the way the pre-questionnaire was designed invited participants to express not only self-perceptions regarding linguistic expertise, but also to indicate the everyday actions they took to supplement explicit and formal language learning. The great majority of students claimed that their primary resources used to continue learning the language on their own were films and television series, rather than books or radio programmes. Genre, medium and topic selection within the iCap project was facilitated by the fact that student sample was an homogeneous group that took an interest in the target culture and relied heavily on the latest audiovisual releases to keep their English up-to-date. In addition, the researcher tried to cater for the participants' tastes in choosing the popular How I Met Your Mother, which was well known and well liked in Spain judging by the number of reruns at the time of the experiment, and this fact may partly explain the high levels of motivation that were achieved, with $80 \%$ of the students finding the activities enjoyable, and $90 \%$ perceiving the activities motivating and declaring that they would be glad to sign up for similar projects in future. 


\subsection{Resources and procedures}

The iCap project was developed in a distance learning setting through aLF, the virtual learning platform used at UNED. In the aLF community created for the project, participants could find the project instructions, the links to the language assessment tests, the videos to be subtitled, the corresponding ClipFlair activities, the discussion forums, and other relevant information.

The project instructions included three phases: pre-activities, activities and postactivities. Participants were required to proceed as follows: (1) complete the initial questionnaire and two language tests -writing and vocabulary pre-tests- as well as become familiar with the ClipFlair platform and the tasks; (2) work on the 10 activities available in the order they were presented, subtitle the videos into English paying attention to condensation and following the instructions contained in the ClipFlair activities (detailed information on how to download the activities and use ClipFlair was also provided); (3) upload each of the finished activities to the appropriate discussion forum thread for peer-review; (4) complete the final questionnaire, the writing and vocabulary post-tests, and take part in a final video conference aimed at providing feedback about the project.

The writing pre-test had to be completed in the first phase and asked students to work on two pieces of writing in 60 minutes. The first written task was a statement to be discussed in essay form (between 100-150 words), while the second task offered three options out of which students should choose one: a blog entry, an e-mail or a magazine contribution (between 130-150 words). As far as the vocabulary pre-test is concerned, it intended to measure productive recall of meaning (Laufer et al., 2004), since students were asked to supply the L2 target word. A total of 50 target words from the 10 video clips were selected for testing. All target words belonged to the Corpus of Contemporary American English (COCA)-Academic (http://corpus.byu.edu/coca) and in particular they pertained to the Core academic, technical and general domains. The pre-test contained 50 target words and 25 distractors. Participants were not aware that they were to be tested again both in written production and vocabulary knowledge at the end of the project.

In the first phase, after taking the tests, participants had time to become familiar with the ten videos to be subtitled. These clips had been carefully selected from the last season of How I Met Your Mother and chronologically ordered. A small team of experts in audiovisual translation and language learning watched all the episodes of the last season of the American sitcom and identified possible scenes that could be fit for the present project. After identifying the scenes, team members would prepare the dialogue transcription and evaluate the scene in terms of its linguistic and paralinguistic appropriateness. Some of the scenes were then discarded and only ten were included in the study. The grounds for rejection included, among others, excessive clip length and inconsistency of content -which would have made the general audiovisual narrative less linear and therefore more difficult to follow and make sense of on the part of the students. Each of the ten selected videos features a self-contained humorous scene that 
can be understood by people who do not know the television series, and it is coded according to its linguistic function (i.e. narrating, requesting, advising, announcing, complaining, justifying, etc.).

In the second phase, which lasted one month, the participants could subtitle the 10 clips at their own pace. As stated in the general instructions of each ClipFlair activity (figure 1), participants were asked to subtitle the English video extracts into English. The steps to be followed were: watch the whole video first and then write the subtitles. It was pointed out that the subtitles should be a condensation (i.e. the gist) and not a transcription of the dialogue. To this end, it was necessary to summarize the main message. In other words, the subtitles should contain the main pieces of information that could help the audience follow the story without missing the visual information. In addition, technical advice was provided and participants were suggested to segment the subtitle lines considering complete sense blocks or grammatical units. Once the video was subtitled, participants were required to upload the activity in the forum for peerreview. Collaboration was fostered during the whole project as participants were encouraged to guide and help each other in order to improve their own performance.

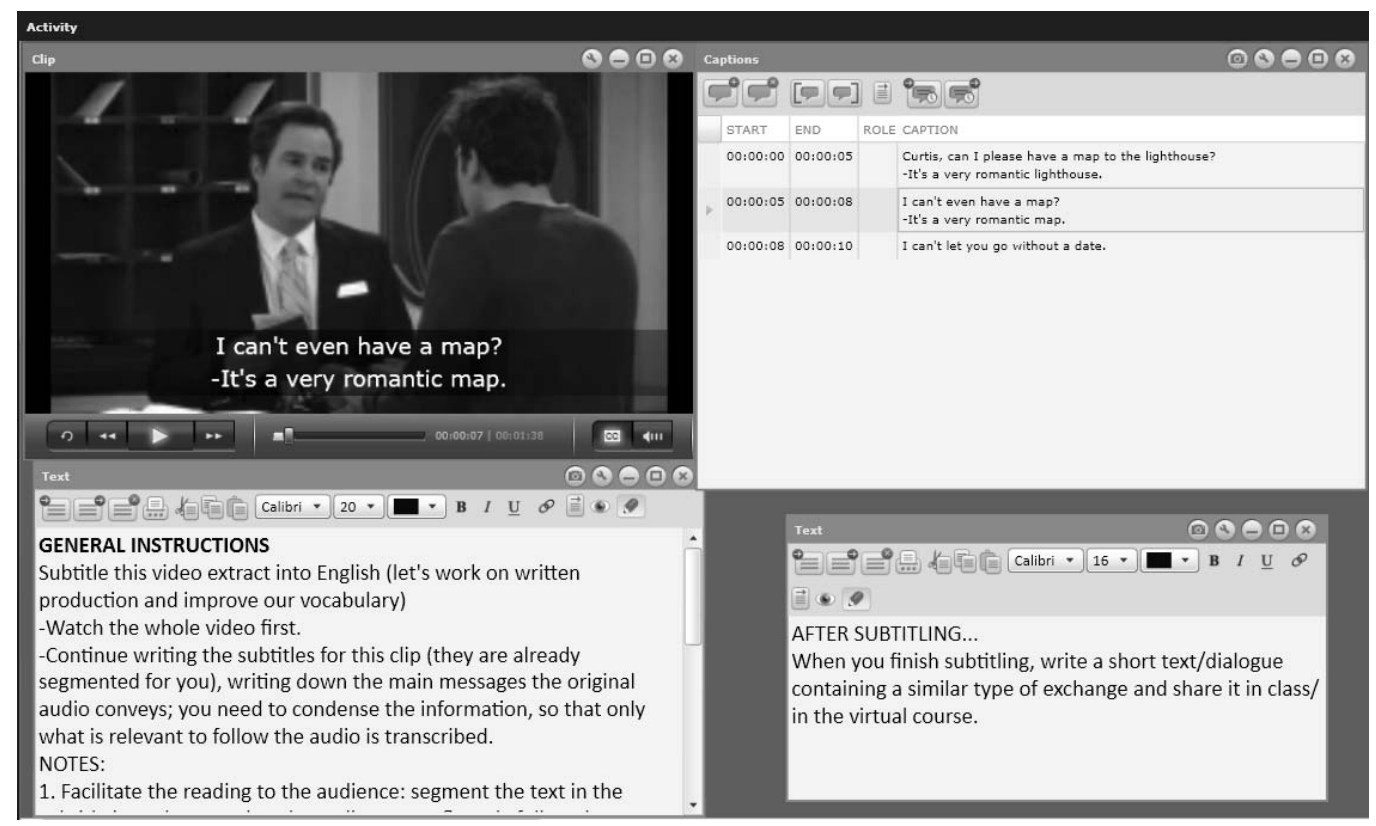

Figure 1. ClipFlair activity sample

In the third phase, participants had one week to complete the final questionnaire as well as the writing and vocabulary post-tests. The writing post-tests had the same structure as the pre-tests: participants were required to submit two pieces of writing in 60 minutes. The first task was once again a statement to be discussed in essay form (between 100-150 words), and the second gave three options out of which students should choose one: a letter of complaint, an e-mail or an online shop review (between 130-150 words). After completing the writing tasks, participants were asked to take a 
vocabulary post-test, which was identical to the vocabulary pre-test but presented the 50 target words in a different order. Finally, all participants were invited to take part in a final video conference to provide feedback about the project. This online meeting was meant to be an opportunity for participants to chat with two of the teachers and other peers and to exchange their opinions about the project both in oral and written form.

\section{Data analysis}

Two different types of language assessment tests were used as instruments of data collection, since the extent of both writing and vocabulary enhancement derived from the use of intralingual subtitling was to be assessed. Hence, the analysis below is divided into two sections, one for each L2 skill.

The observers who assessed the writing tests (pre and post) followed a specific rubric designed for the project, drawing from Cohen et al. (2011), Council of Europe (2001), Cushing (2002) and Hyland (2010). The rubric provided a total of 50 marks (25 per task) and was divided into 5 descriptors: readability, coherence, cohesion, length and general impression. Each of them was explained and detailed from 5 to 1 (with the corresponding equivalences described) and a suggested marking chart was also facilitated, as well as relevant notes on possible penalizations (for misspellings, inappropriate use of verb tenses, incorrect use of prepositions, pronoun forms confusion, etc.) to be considered for B1 level written production.

The average marks of the 41 participants and the corresponding standard deviation derived after analysing the marking charts of two observers are provided in table 1.

\begin{tabular}{|l|l|l|}
\hline & Pre-test & Post-test \\
\hline Average mark & 6.77 & 7.21 \\
\hline Standard deviation & 1.16 & 1.25 \\
\hline
\end{tabular}

Table 1. Written production tests data

Although no control group was available for this study in particular, the remarkable increase regarding the students' writing skills in such a short time span (one month and a half), bearing in mind that the students worked online in a distance learning environment, is undoubtedly of notice. These results are confirmed and accompanied by information regarding marks correlation, a characterization analysis and the hypothesis testing detailed below.

A brief correlation study was used here to confirm a reasonable evidence of a causal relationship (Cohen et al., 2011) among the marks obtained in the written production tests. To characterise this correlation, Pearson's coefficient (Peña and Romo, 1997) was used to determine whether any significant correlation could be found between the marks of the pre-test and the post-test so as to check whether there was a direct relation of 
improvement in the group as a whole; the correlation was quite close to 1 (0.77), which confirms that the improvement was general and consistent, so it can be derived that the course of the experiment in this regard developed as expected, as shown in figure 2.

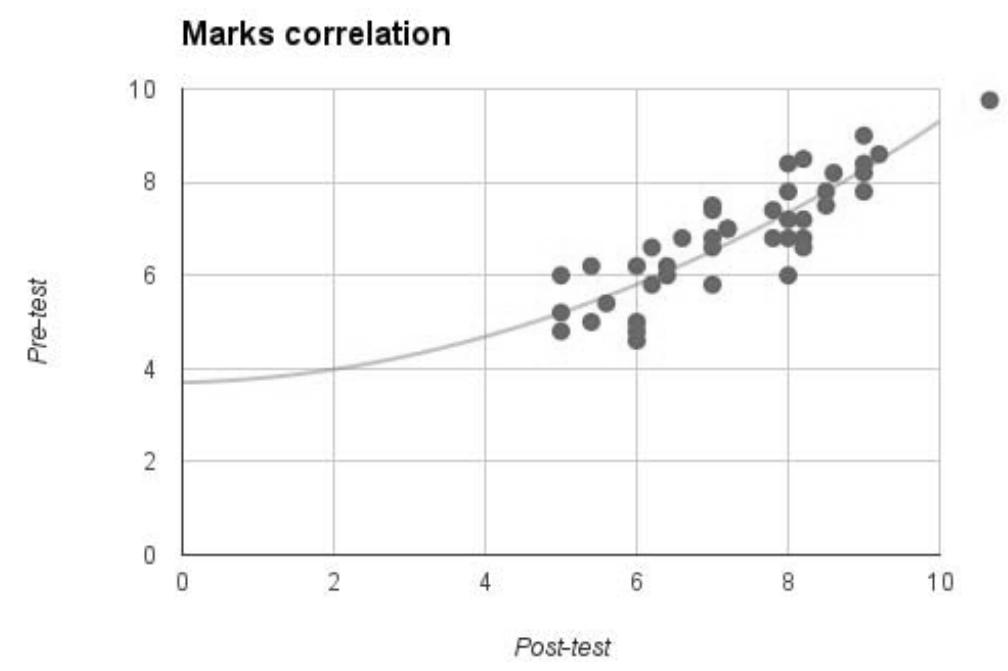

Figure 2. Written production tests direct marks correlation

A characterisation analysis of the average marks was also performed to complement the previous data. In this case, the Gaussian bell curve was used to check whether the marks followed a normal distribution. As shown in figure 3, the distribution of marks follows the expected curve, since it becomes less regular after the activity, where some students improved more than others (this goes parallel with the slight increase of the standard deviation observed in table 1).

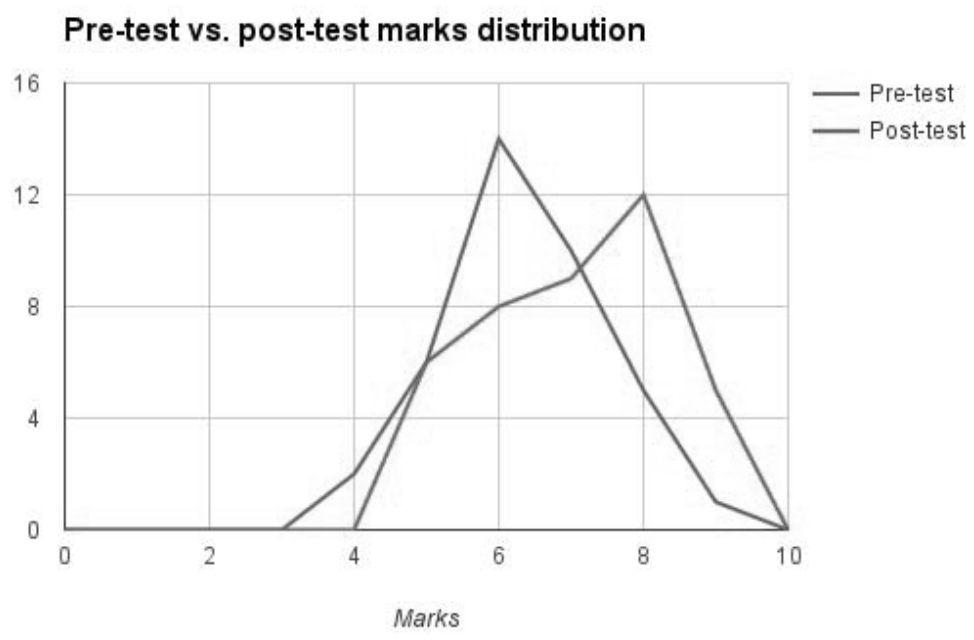

Figure 3. Pre-test vs. post-test marks distribution 
To close the analysis on the written production results, a hypothesis test was carried out, where two hypotheses were established (null hypothesis and alternative hypothesis). The critical or rejection region was determined, i.e. the set of values of the test for which the null hypothesis could be rejected, and a normal distribution of the population was assumed (something that was gathered from the data provided in the previous paragraphs). Table 2 shows the set of reference levels (confidence and critical) which were applied:

\begin{tabular}{|c|c|c|c|}
\hline Confidence level $\mathbf{N}_{\mathbf{C}}$ & $90 \%$ & $95 \%$ & $99 \%$ \\
\hline Critical value $\mathbf{z}_{\mathbf{C}}$ & 1.28 & 1.645 & 2.33 \\
\hline
\end{tabular}

Table 2: Reference levels

The hypothesis test was performed using the formula in figure 4.

$$
z=\frac{\left(\bar{x}_{B}-\bar{x}_{A}\right)}{\sqrt{\frac{\sigma_{A}{ }^{2}}{N}+\frac{\sigma_{B}{ }^{2}}{N}}}
$$

Figure 4. Critical value formula

The value obtained for $z, 1.69$, is compared with the critical value and so the null hypothesis is rejected with a high confidence level (95\%); thus, the alternative hypothesis can be said to be true, proving that something has happened, in other words, that changes have been produced, i.e. an improvement of written production skills, confirming and triangulating the previous findings.

Hence, from a primary quantitative perspective, it could be derived that intralingual subtitling in L2 can improve writing skills in online settings. This preliminary statement will be recovered afterwards and qualitative data -obtained both from the postquestionnaire and from observation- will try to provide evidence for confirmation and contrast.

Turning now to the data obtained from the vocabulary tests, it should be noted that vocabulary knowledge involves various aspects that must be borne in mind: knowledge of form, knowledge of meaning as well as knowledge of use as stated by Nation (2001: 27). Of course form, meaning, and use of a word can be both receptive and productive. Since meaning seems to be the first and most important element involved in knowing a word, the focus here was on the meaning-form aspect. For testing purposes, Laufer et al. (2004) identified 4 degrees of knowledge of meaning based on the following two dichotomous distinctions: productive vs. receptive (active vs. passive) and recall vs. recognition. In the present scenario, the focus was on productive recall of meaning, i.e. 
students were required to supply the L2 target word. As previously mentioned, a total of 50 target words from the 10 video clips were selected for testing, all of them pertaining to Core academic, technical and general domains. The pre-test included both the 50 target words as well as 25 distractors so that students did not focus and thus remembered the 50 selected items in view of the post-test. The post-test featured only the 50 target words in a different order. Although 70 participants completed the vocabulary pre-test, only 41 of them completed the post-test. Out of this group a subgroup of 9 participants, who did not know three of the target words, was selected for the analysis that is included in table $3 .^{2}$

\begin{tabular}{|c|c|}
\hline \multicolumn{2}{|c|}{ Vocabulary recall sample } \\
\hline TW1 & 9 \\
\hline TW2 & 5 \\
\hline TW3 & 3 \\
\hline Table 3. Vocabulary data analysis (sample) \\
\hline
\end{tabular}

Table 3 shows how many participants of the subgroup could productively recall the meaning of three target words (TW1, TW2 and TW3) in the post-test. Target word 1 was correctly recalled by all subgroup participants (100\%), while target word 2 by $55 \%$ of them and as many as $33 \%$ of the participants could provide target word 3 . The difference in words recall could be due to the fact that the most recalled word was related to something relevant to the development of the story in the videos. The results from this subgroup analysis on word meaning productive recall after the experimental study are encouraging, considering that the participants did not know that they would be tested again on the target words and thus did not pay particular attention to them while carrying out the intralingual captioning tasks. It must be also noted that every target word appeared only once in a single clip. Indeed, the results from the analysis show that after one month of exposure to the words -the time allocated to the subtitling of the videos- subgroup participants could successfully recall a relevant number of target words. Therefore, further (more controlled) testing to shed more light on the effects of intralingual subtitling on vocabulary meaning productive recall is recommended. To this regard, it is advisable to implement a pilot study to determine the pool of target words and to plan a delayed vocabulary post-test to verify the level of long-term recall.

Finally, the results analysed can be contrasted and supported by qualitative data in the form of participants' responses regarding their improvement in the main L2 skills, and in particular those related to written production and vocabulary knowledge, as shown in figure 5. 


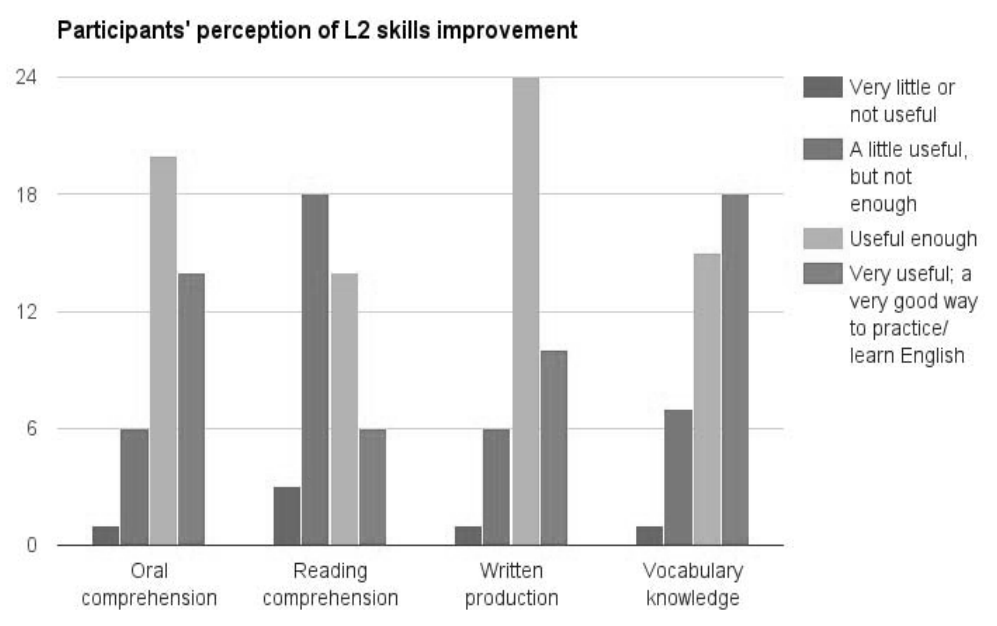

Figure 5. Participants' perception of L2 skills improvement

From the above representation, it is noticeable how most students felt listening comprehension was the skill that benefited the most from the activity of subtitling, as previous studies had already advanced (Talaván, 2011 and Talaván \& RodríguezArancón, 2015). However, it is also remarkable how intralingual subtitling is seen as 'useful enough' or 'very useful' to improve written production and vocabulary learning; in fact, vocabulary knowledge has the highest peak in terms of participant's perception of "a very good way to practice/learn English" so that the previous data that was taken somewhat tentatively, is hereby complemented. Hence, we can conclude that the students' perceptions confirm the data previously analysed, inasmuch as both skills are perceived as enhanced thanks to the project. In the discussion section below, further insights in this regard will be provided accompanied by the corresponding information obtained from the last instrument of data collection to be detailed: observation.

\section{Discussion}

Each of the stages in the project offered significant results to back the hypothesis that intralingual subtitling may be used as a language learning tool. It should be noted that, from start to finish, the project as a whole was a demanding endeavour both for participants and for the teaching team who designed the activities, readied the questionnaires, intervened in the forums, prepared the assessment rubrics and corrected the students' work. Notwithstanding, part of the innovative character of the project, apart from its promising results, ease of replicability and pedagogical benefits, resides in its collaborative nature: language experts from several European institutions, doctoral students and other professionals worked shoulder to shoulder for a period of over six 
months from the moment the project was conceived until the final data were interpreted to obtain valid and reliable results that could later be discussed and contrasted objectively. According to the opinions reflected in the post-questionnaire, this commitment bore fruit, with $93 \%$ of participants stating that the project had met their expectations -which were improving their vocabulary, and receptive as well as productive English skills- even when $46 \%$ of them had found subtitling the clips a bit hard in linguistic terms and had stumbled upon some kind of technical problem at least on one occasion.

A total of 200 hours of work on the part of the students, forum managers and assessment experts were registered in the UNED virtual platform, which measures the number of minutes each individual stays connected -after signing in with their personal password- doing actual work, that is to say, writing comments in the forums, uploading files, or assessing work rather than simply accessing content and remaining static. In light of the relatively small size of the sample, these data reveal that quantitatively as well as qualitatively speaking such high levels of motivation are neither arbitrary nor casual. Interestingly, those 200 hours do not include the actual time participants spent subtitling the clips but only commenting on them and receiving suggestions for improvement. Platform minutes started counting only after the students uploaded draft versions and finished materials; the subtitling process itself should be accounted for separately. If we were to assume that subtitling a two to two-and-a-half minute unscripted clip takes a beginner between 35 and 50 minutes to complete on average, finishing the whole batch would take at least ten times that. Additionally, it was the participants' responsibility to discuss their idiosyncratic choices, improve their drafts with the help of their peers and teachers, re-upload their final versions, reflect upon culturally-bound elements that were challenging to understand, complete the questionnaires, the tests and participate in the final half-hour videoconference. From start to finish, then, taking part in the project meant that each student should set apart at least 12 hours over a period that effectively amounted to just half a term, holidays included. This might explain why only a third of participants could finish all of the tasks in the time allocated for that purpose.

As for the participants' reception of the project and the degree to which their expectations were met, the post-questionnaire returned very positive responses. Almost $80 \%$ of the participants indicated that their oral receptive skills (listening) and vocabulary had noticeably improved, while $70 \%$ claimed that their written production skills were better or much better after the project; it should be noted that they had been given the opportunity to carry out a regular peer-to-peer assessment through the active use of forums, they had had the possibility of discussing their choices with members of the teaching team, and they had further developed competences such as finding information independently, making sure that the information was accurate and reliable, sharing their results with others, reaching compromises, self-correcting, and identifying culture-bound linguistic items, all of which were seen as essential for the studies they were enrolled in. Subtitling a single video, or, to put it another way, receiving, processing, managing and synthesising information obtained from a diversity of 
channels -visual, auditory and textual- inevitably required the activation of all these competences in simultaneity, together with rigorous terminological discernment. The participants' willingness to carry on with their subtitling work even after the project ended and their increased capacity to perceive the effort that subtitlers put into their work stands as a strong confirmation of attitudinal change. In the words of one student during the final videoconference: '[subtitling] was something I didn't really know much about before this project started, but now that I know the programmes and what it is for, I'll do it again for sure'.

For this sample of 41 students, subtitling a series of short clips intralingually taught them how to convey a message differently and more succinctly, to determine whether what they saw as the main point, the gist of a particular text fragment, was the same as that of their peers and, when that was not the case, to reconsider their own choices or to persuade others to see things another way. These aspects help explain why seven out of ten participants felt more confident using English to communicate with others than when they started. In sum, more than two thirds of participants believed the project had contributed to improving their linguistic skills, especially writing and vocabulary, that they were better able to find accurate solutions to linguistic problems while working on their own, and that subtitles were a motivating tool they would definitely try again.

\section{Conclusions}

This paper has undertaken a groundbreaking research by exploring the potential of intralingual subtitling tasks in foreign language education using the web platform ClipFlair. Starting from the premise that producing same-language subtitles in the L2 can be beneficial to language learning, this study put forward that intralingual captioning in a distance learning context can enhance writing-related skills -such as register and style selection, sequencing of ideas, correct use of cohesion and coherence, and spelling- and vocabulary acquisition in terms of meaning recall.

In order to provide greater reliability, the present study has employed a quasiexperimental research design that has led to a triangulation of data, methods and observers. The quantitative analysis of the language assessment tests, supported by participants' answers to initial and final questionnaires, as well as to a qualitative analysis of observation, have reported encouraging results regarding the use of intralingual subtitling as an L2 learning resource both for writing skills improvement and vocabulary acquisition. Participants showed their appreciation for this innovative project by dedicating a considerable amount of their time to carry out the intralingual subtitling tasks, providing peer-to-peer assessment through the online forums and completing the required language tests and questionnaires. This was also confirmed by their interest in continuing to practise subtitling and their willingness to participate in more AVT projects. In addition, participants enjoyed the project as this task-oriented cooperative work in an online learning context boosted their motivation. 
On the other hand, the study presents some limitations. As previously discussed, the iCap project was designed and developed by an international team of researchers for a period of over six months. Due to time and resources constraints, it was not possible to carry out a pilot study and this affected the vocabulary assessment test since the target word pool had to be drastically reduced. Moreover, it was not possible to have a control group. Also, although the project initially had a promising large experimental group of 70 undergraduates, the number of participants who completed all the required activities was 41 . The students' withdrawal could be ascribed to the tight deadlines (the project lasted one month and a half) and the demanding tasks required (clip subtitling, peer-topeer assessment, writing and vocabulary pre- and post-tests, and initial and final questionnaires). Likewise, an assessment of the student's subtitle production (410 subtitle files) would have provided further relevant data to complement observation.

The promising outcome of this study definitely encourages further research on intralingual captioning in language learning. Research on intralingual captioning can focus on different aspects of writing and vocabulary acquisition; on enhancing other language skills, in particular, listening comprehension and oral production; even on different learning contexts such as face-to-face and blended learning; or on language learners of diverse languages and levels over longer periods of time. Other AVT modes could also be investigated, such as subtitles for the deaf or hard-of-hearing (SDH) as another subtitling task yet to be explored, or even dubbing and audiodescription as revoicing tasks. In this regard, three recent projects have been undertaken at the UNED within a Teaching Innovation Research Network comprising a number of external partners: the RECORDS-Revoicing to Enhance Oral Production Skills project has obtained reasonably valid conclusions that shed some light on the pedagogical benefits of online collaborative audiodescription to develop oral production skills in undergraduate students of English for Specific Purposes (Talaván and Lertola, 2016); the iDub-Intralingual Dubbing project has attempted to assess the potential of dubbing using ClipFlair to develop general oral production skills in adult university students of English (B2 level) in a distance learning environment (Talaván and Costal, 2017); and the SubLITE-SUBtitles for the Deaf and Hard of Hearing project has focused on the improvement of LIstening and wriTing Skills in foreign language Education, and is still in the process of data gathering.

Experimental research on the feasibility of improving language learning processes in formal education has been carried out with small numbers of university graduates and undergraduates or upper-secondary students in non-longitudinal studies. The advent of a European standard norm for subtitling will perhaps be made possible once generalisable, statistically significant, reliable, valid and longitudinal studies have to offer definite conclusions on the level of enhancement this technique has for language users. Notwithstanding, higher numbers of participants and longer spans of time require larger teams of experimenters and the continued support of both public and private institutions. The promising results of the present paper, together with those studies of a similar nature which have given insight into the incontrovertible advantages of 
audiovisual modalities as an essential part of language learning methodologies, invite the establishment of more ambitious research projects at a supranational level.

\section{Notes}

1. The concept of 'intensive listening' is referred to here in the same terms as in Buck (2001) and Rost (2011).

2. Due to the reduced number of participants in the vocabulary post-test and the impossibility of previously conducting a vocabulary pilot study on a sample, the number of target words for the present study was reduced. Contrary to what was expected, several students knew the meaning of many target words selected. The largest group of people who did not know the same words ( 3 in total) was a group of 9 participants.

\section{References}

Borghetti, Claudia and Jennifer Lertola (2014): "Interlingual subtitling for Intercultural Language Education: A Case Study". Language and Intercultural Communication, 14(4): 423-440.

Buck, Gary (2001): Assessing Listening. London: CUP.

Cohen, Louis, Manion, Lawrence and Keith Morrison (2011): Research Methods in Education. London: Routledge.

Council of Europe. (2001): Common European Framework of Reference for Languages: Learning, Teaching, Assessment. Strasbourg: Language Policy Unit.

Cushing, Sara (2002): Assessing Writing. London: CUP.

Danan, Martine (2015): "Subtitling as a Language Learning tool: Past Findings, Current Applications, and Future Paths". In Yves Gambier, Annamaria Caimi, and Cristina Mariotti, eds., Subtitles and Language Learning: Principles, Strategies and Practical Experiences. Bern: Peter Lang, 41-61.

European Commission (2009): Study on the Use of Subtitling. The Potential of Subtitling to Encourage Foreign Language Learning and Improve the Mastery of Foreign Languages EACEA/2009/01. Brussels: Directorate General of Education and Culture.

European Commission (2012): Studies on Translation and Multilingualism. Crowdsourcing Translation. Luxembourg: Publications Office of the European Union.

European Commission (2013): Studies on Translation and Multilingualism. Translation and Language Learning: The Role of Translation in the Teaching of Languages in the European Union. Luxembourg: Publications Office of the European Union.

Hyland, Ken (2010): Teaching and Researching Writing. London: Longman.

Incalcaterra McLoughlin, Laura (2009): "Subtitles in Translators' Training: A Model of Analysis". Romance Studies, 27(3): 174-185.

Incalcaterra McLoughlin, Laura and Jennifer Lertola (2014): "Audiovisual Translation in Second Language Acquisition. Integrating Subtitling in the Foreign-language Curriculum". In S. Laviosa (ed.) Translation in the Language Classroom: Theory, Research and Practice, special issue of The Interpreter and Translator Trainer, 8(1): 70-83. 
Laufer, Batia, Elder, Cathie, Hill, Kathryn and Peter Congdon (2004): "Size and Strength: Do We Need Both to Measure Vocabulary Knowledge?" Language Testing, 21(2): 202-226.

Lertola, Jennifer (2012): "The Effect of the Subtitling Task on Vocabulary Learning", in Anthony Pym and David Orrego-Carmona, eds., Translation Research Projects 4. Tarragona: Intercultural Studies Group, 61-70.

López Cirugeda, Isabel and Raquel Sánchez Ruiz (2013) "Subtitling as a Didactic Tool. A Teacher Training Experience". Porta Linguarum, 20: 45-62.

Nation, Paul (2001): Learning Vocabulary in Another Language. Cambridge: Cambridge University Press.

Massidda, Serenella (2015): Audiovisual Translation in the Digital Age: The Italian Fansubbing Phenomenon. Basingstoke: Palgrave MacMillan.

Pavesi, Maria (2012): "The Potentials of Audiovisual Dialogue for Second Language Acquisition", in Pilar Alderete-Díez, Laura Incalcaterra McLoughlin, Labhaoise Ní Dhonnchadha and Dorothy Ní Uigín, eds., Translation, Technology and Autonomy in Language Teaching and Learning. Oxford: Peter Lang, 155-173.

Peña, Daniel and Juan Romo (1997). Introducción a la estadística para las ciencias sociales [Introduction to Statistics for the Social Sciences]. Madrid: McGraw Hill.

Rost, Michael (2011): Teaching and Researching Listening. London: Longman.

Sokoli, Stavroula (2015): "ClipFlair: Foreign Language Learning through Interactive Revoicing and Captioning of Clips", in Yves Gambier, Annamaria Caimi, and Cristina Mariotti, eds., Subtitles and Language Learning: Principles, Strategies and Practical Experiences. Bern: Peter Lang, 127-148.

Talaván, Noa (2006): "Using Subtitles to Enhance Foreign Language Learning”. Porta Linguarum, 6: 41-52.

Talaván, Noa (2011): “A Quasi-Experimental Research Project on Subtitling and Foreign Language Acquisition”. In L. Incalcaterra McLoughlin, M. Biscio, and M. Á. Ní Mhainnín, eds., Audiovisual Translation Subtitles and Subtitling. Oxford: Peter Lang, 197-218.

Talaván, Noa (2013): La subtitulación en el aprendizaje de lenguas extranjeras [Subtitling in foreign language learning]. Barcelona: Octaedro.

Talaván, Noa and Pilar Rodríguez-Arancón (2014): "The Use of Reverse Subtitling as an Online Collaborative Language Learning Tool". In Sara Laviosa (ed.) Translation in the Language Classroom: Theory, Research and Practice, special issue of The Interpreter and Translator Trainer, 8(1): 84-101.

Talaván, Noa and José Javier Ávila Cabrera (2015): "First Insights into the Combination of Dubbing and Subtitling as L2 Didactic Tools". In Yves Gambier, Annamaria Caimi, and Cristina Mariotti, Subtitles and Language Learning: Principles, Strategies and Practical Experiences. Bern: Peter Lang, 149-172.

Talaván, Noa and Pilar Rodríguez-Arancón (2015): “The Use of Interlingual Subtitling to Improve Listening Comprehension Skills in Advanced EFL Students". In Beatrice Garzelli and Michaela Baldo, eds., Subtitling and Intercultural Communication. European Languages and beyond. Pisa: InterLinguistica, ETS, 273-288.

Talaván, Noa and Jennifer Lertola (2016): “Active Audiodescription to Promote Speaking Skills in Online Environments". Sintagma, 28: 59-74.

Talaván, Noa, Ana Ibáñez and Elena Bárcena (2016): "Exploring collaborative reverse subtitling for the enhancement of written production activities in English as a second language". ReCALL, 29(1): 39-58. 
Talaván, Noa and Tomás Costal (2017). “iDub - The Potential of Intralingual Dubbing in Foreign Language Learning: How to Assess the Task". Language Value, Special Issue on Teaching With Technology: Forthcoming.

Vanderplank, Robert (2015): "Thirty Years of Research into Captions/Same Language Subtitles and Second/Foreign Language Learning: Distinguishing between "Effects of" Subtitles and "Effects with" Subtitles for Future Research", in Yves Gambier, Annamaria Caimi, and Cristina Mariotti, eds., Subtitles and Language Learning: Principles, Strategies and Practical Experiences. Bern: Peter Lang, 19-40. 